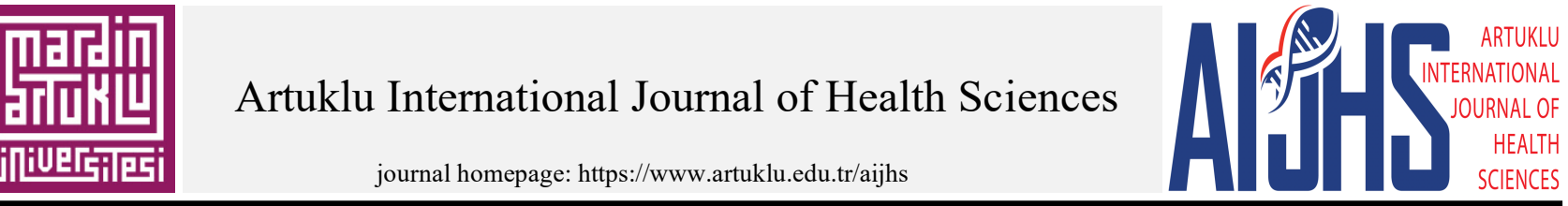

Derleme / Review

\title{
Sessiz Başlayan - Ölümle Sonuçlanabilen Ciddi Bir Koma: Addison Krizi
}

\section{A Serious Coma Starting Silently and Could Result in Death: Addison Crisis}

\author{
Hülya Keskin ${ }^{\mathrm{a}^{*}}$, Aynur Türeyen ${ }^{\mathrm{b}}$ \\ a Dr.Öğretim Üyesi, Mardin Artuklu Üniversitesi, ORCID: https://orcid.org/0000-0003-3897-0814 \\ "İletişimden sorumlu yazar, E-mail: hulya_k@hotmail.com \\ ${ }^{b}$ Prof. Dr., Ege Üniversitesi, ORCID: https://orcid.org/0000-0002-2361-2099
}

\section{ARTICLE INFO}

Article History:

Received 08.07.2021

Received in revised form 16.07.2021

Accepted 21.07.2021

Keywords:

Adrenal crisis

Addison

Nursing

\begin{abstract}
Addisonian crisis, also known as adrenal crisis or acute adrenal insufficiency, occurs in patients who have hypotension and shock, who have not been diagnosed before, or whose compliance with treatment is impaired despite being diagnosed, or who have encountered stress. Adrenal crisis is a serious clinical condition that starts silently, progresses rapidly and insidiously, however, can result in death by causing serious consequences, and requires urgent and effective care management. Therefore, there is need to have knowledge and awareness regarding adrenal crisis in the team working in the emergency department, especially in internal medicine, endocrine and emergency nurses. The main purpose of this study, which is planned with these thoughts; to increase the knowledge and awareness of nurses working in internal medicine clinics, especially nurses working in emergency department and endocrine clinics, regarding the adrenal crisis, to create resources for effective nursing management planning while giving care to adrenal crisis cases, and to contribute to the literature on the adrenal crisis.
\end{abstract}

(c) 2021 Mardin Artuklu University. All rights reserved.

\section{MAKALE BİLGILERI}

\section{Makale Geçmiși:}

Gelis Tarihi: 08.07.2021

Revizyon Tarihi: 16.07 .2021

Kabul Tarihi: 21.07.2021

Anahtar Kelimeler:

Adrenal kriz

Addison

Hemşirelik

\section{ÖZET}

Addison krizi başka bir tanınmıș adı ile adrenal kriz ya da akut adrenal yetmezlik; hipotansiyon ve şok tablosu olup, daha önceden tanı almamış veya tanısı olduğu halde tedaviye uyumu bozulan ya da stres ile karşılaşmış hastalarda ortaya çıkar. Adrenal kriz sessiz başlayan, hızlı ve sinsi ilerleyen ancak ciddi sonuçlara neden olarak ölümle sonuçlanabilen ağır bir klinik durumdur ayrıca acil ve etkin bakım yönetimi gerektirir. Bu bağlamda acil servis ekibinde özellikle de dahiliye, endokrin ve acil servis hemșirelerinde adrenal kriz ile ilgili bilgi ve farkındalık gerektirmektedir. Bu düşüncelerle planlanan bu makalenin temel amacı; özelikle acil ve endokrin kliniğinde çalışan hemşireler olmak üzere dahiliye kliniklerinde görevli hemşirelerin adrenal kriz ile ilgili bilgi ve farkındalığını arttırmak, adrenal kriz olgusuna bakım verirken etkin bir hemşirelik yönetimi planlamaları için kaynak oluşturmak ve adrenal kriz ile ilgili literatüre katkı sağlamaktır.

\section{Giriş}

Addison krizi ya da daha tanınmış adları ile akut adrenal yetmezlik ya da adrenal kriz; birçok organı etkileyen ve hayatı tehdit eden ciddi bir sağlık sorunudur (1). Diğer deyişle adrenal kriz, uygun şekilde tanı konulmadığı ve erken tedavi edilmediği takdirde, yüksek mortalite ile ilişkili, yaşamı tehdit eden tıbbi bir acil durumdur (2).

Primer veya sekonder adrenal yetmezliği olan hastalarda yılda her 100 hastanın yaklaşık 5-17'sinde adrenal kriz ortaya çıkmakta ve kadınlarda daha sık görülmektedir (3). Yaklaşmakta olan bir adrenal krizin sağlik personeli tarafından geç fark edilmesi veya evde ya da dışarda meydana gelen bir adrenal krizin acil servise geç getirilmesi dolayısı ile hidrokortizon tedavisinin zamanında yapılamaması, araştırma hastanelerinde bile yaygın olarak karşılaşılan bir durum olmaya devam etmektedir. Konu ile ilgili uluslararası ve ulusal alan yazın incelendiğinde, adrenal krize yönelik daha çok olgu sunumlarına ve tıbbi yönetime yönelik çalışmaların yer aldığı ancak hemşirelik yönetimine yönelik yayınların sınırlı sayıda olduğu belirlenmiştir (4)(5)(6)(7)(8).

Amaç: Adrenal kriz sessiz başlayan, hızlı ve sinsi ilerleyen ancak ciddi sonuçlara neden olarak ölümle sonuçlanabilen ağır bir klinik durumdur ayrıca acil ve etkin bakım yönetimi gerektirir. 
Bu bağlamda acil servis ekibinde özellikle de dahiliye, endokrin ve acil servis hemşirelerinde adrenal kriz ile ilgili bilgi ve farkındalık gerektirmektedir. $\mathrm{Bu}$ düşüncelerle planlanan bu makalenin temel amac1; özelikle acil ve endokrin kliniğinde çalışan hemşireler olmak üzere dahiliye kliniklerinde görevli hemşirelerin adrenal kriz ile ilgili bilgi ve farkındalığını arttırmak, adrenal kriz olgusuna bakım verirken etkin bir hemşirelik yönetimi planlamaları için kaynak oluşturmak ve adrenal kriz ile ilgili literatüre katkı sağlamaktır.

\subsection{Adrenal Kriz}

Adrenal bez, korteks ve medulla olmak üzere iki kısımdan oluşur. Adrenal korteksden glikokortikoid, mineralokortikoid, androjen ve östrojenler salgılanır. Adrenal medulladan ise Adrenalin (Epinefrin) ve Noradrenalin (Norepinefrin) diğer adıyla katekolaminler salgılanmaktadır. Adrenokortikal hormonlar yaşamın devamı için önemli bir fonksiyona sahiptir (9)(10)(2). Özellikle glikokortikoidler strese cevap reaksiyonunda önemli role sahiptir ve hemodinamik dengeyi sağlamaktadır. Addison krizi ya da diğer adları ile adrenal kriz ya da akut adrenal yetmezlik; birçok organı etkileyen, hayatı tehdit eden ciddi bir kriz durumudur. Adrenal kriz, katekolamine dirençli ciddi hipotansiyon ve şok tablosu olup; daha önceden tanı almamış veya tanıs1 olduğu halde tedaviye uyumu bozulan ya da büyük fizyolojik stres ile karşılaşmış hastalarda ortaya çıkan bir tablodur (11). Hastalığa adını veren Thomas Addison, bu hastalığı 1855 'te 11 vakada kriz ile tanımladığında, iki taraflı adrenal yetersizliğin en sık nedenini tüberküloz olarak belirtmiştir. Günümüzde ise vakaların sadece \%7-20'sinden tüberküloz sorumlu olup, \%7090'ının otoimmun kaynaklı olduğu belirlenmiştir. Addison hastalığının prevalansı 35-60/120 milyon kişi olarak düşünülmekte; ancak toplam olarak 120 milyon kişinin addison hastalığından etkilendiğini belirten verilere de rastlanmaktadır. Addison hastalığı olan hastalarda adrenal kriz değerlendirmesi yapılan çalışmalar incelendiğinde ise; örneğin Norveç verileri genel olarak addison hastalığ olan 7 hastadan 1'inin sonunda adrenal krizden öldüğünü göstermektedir (9). Bu ölümlerin genellikle acil serviste veya yoğun bakım ünitesinde yatan nispeten genç hastalar olduğu belirlenmiştir. Ölüm nedenlerinin ise; tanının geç konulması, yetersiz steroid replasmanı sonrasında gelişen hipovolemik şok, kardiyak-solunum arresti olduğu saptanmıştır. Burada en önemli nokta mortaliteye neden olan faktörlerin aslında önlenebilir olmasıdır.

Adrenal krizin patogenezinde, adrenal bezlere yetersiz kan akımı, adrenal ve hipofiz işlevlerinin baskılanmasını sağlayan mediyatörlerin salgılanması önemli role sahiptir.
Adrenal kriz, primer adrenal yetmezlik ve sekonder-tersiyer yetmezlik olarak iki şekilde ortaya çıkmaktadır. Primer adrenal yetmezlik; adrenal bezlerin hasara uğramasından, sekondertersiyer adrenal yetmezlik ise hipotalamo-hipofizer sistemin hasarlanmasına bağlı olarak ortaya çıkmaktadır. Her iki durumda da serum kortizol düzeyinde azalma olmaktadır. Primer adrenal yetmezlik, milyonda 120'lik bir insidans ile nispeten nadir bir hastalıktır (12). Adrenokortikal yetersizliğin akut olarak ortaya çıkması şeklinde olabileceği gibi, kronik olarak seyretmekte olan yetersizliğin enfeksiyon, travma, cerrahi girişim, myokard infarktüsü gibi bir nedenle provoke olmasıyla da gelişebilir. Bununla birlikte, risk altındaki en büyük hasta grubu; kronik steroid kullanan hastalardır. Bu hastalarda ilerleyen dönemlerde sıklıkla adrenal baskılanma gelişmektedir ve böylelikle akut stres/hastalık sırasında endojen kortizol düzeylerini yeterince yükselmediği için akut adrenal kriz ortaya çıkmaktadır (11).

Adrenal krizde adrenal kortekste bulunan üç tabaka da etkilenir. Temel sorunlar; glukokortikoid, mineralokortikoid, androjen eksikliği ve melanin pigmentasyonudur. Addison krizinde görülen en önemli ve erken dönem semptomlar; hipotansiyon, bulantı-kusma, karın ağrısı olmakla birlikte halsizlik, yorgunluk, baş ağrısı, anoreksiya, dehidratasyon, hiperpigmentasyon, diyare ve aşırı tuz yeme isteği gibi yakınmalar da görülebilmektedir. Hafizada azalma, apati, mental durgunluk, konfüzyon, deliryum ve stupor gibi organik beyin sendromu bulguları, depresyon ya da psikoz gibi ruhsal değişiklikler de gözlenebilir (13)(11). Bulgular korteksten salınan hormonların eksikliğine bağlı görülmekte olup; glukokortikoid eksikliğine bağlı açlık, ölümcül hipoglisemiye yol açabilir. Bunların yanısıra siyanoz, ateş ve klasik şok belirtileri de vardır. Mineralokortikoid eksikliğine bağlı sodyum böbreklerden atılırken, potasyum tutulur ve plazmada potasyum yükselir. Plazma sodyumunun azalması ile plazma hacmi de azalır; hipotansiyon, dolaşım yetmezliği ile hastanın durumu sonuçta şoka kadar ilerleyebilir. Melanin pigmentasyonu bulguları olan derinin yaygın esmerleşmesi görülür. Vücudun güneşe ve basınca maruz kalan bölgelerinde, eklemlerin üzerinde ve özellikle avuç içi ve kıvrımlarında aşırı pigmentasyon gözlenmektedir. Laboratuvar bulgularına sık olarak hiponatremi, hiperkalemi, hipoglisemi, lenfositoz ve eosinofili eşlik eder (14).

\subsection{Adrenal Krizde Tedavi}

Addison krizinde eğer hastada primer ya da sekonder adrenokortikal yetmezlik tanısı daha önceden konulmuş ise tedaviye direkt olarak acilen başlanmalıdır. Adrenokortikal yetmezlik tanısı şüpheli ise tedaviye başlamadan önce; 
laboratuvar incelemeleri için hemen serum örnekleri alınmalı ve tedavi geciktirilmemelidir. Adrenal krizinin acil tedavisi; kortikosteroid replasman1, hipoglisemi mevcut ise $\% 5$ veya $\% 10$ dextroz replasmanı, sıvı açığınının dengelenmesi için izotonik $\mathrm{NaCl}$ enfüzyonu başlanmasını ve bu tedavi süresince elektrolitler, glikoz ve BUN değerlerinin sürekli monitorize edilmesini içermektedir (15) (16).

\subsection{Hemșirelik Yönetimi}

Şoka kadar ilerleyebilen akut adrenal yetmezlik tablosunda hemşirelik bakımının temel ilkeleri; yaşam bulgularının ve sıvı elektrolit dengesizliklerinin değerlendirilmesi ve sonuçlara göre hemşirelik girişimleri uygulanmasıdır. Addison krizinde hemşirelik yönetimi hemşirenin temel sorumlulukları olan primer, sekonder ve tersiyer koruma ilkeleri göz önüne alındığında 3 kategoride değerlendirilebilir.

Primer hemşirelik sorumluluğu; kronik adrenal yetmezlik tanısı alan ya da bu tanıya doğru giden belirtileri gösteren hastalarda olası riskleri göz önüne alarak, detaylı anamnez ve fizik muayene ile hastanın stres durumuna ve sıv1-elektrolit dengesi üzerine odaklıdır. Hastanın ön belirti ve bulgularını dikkatlice gözlemleyerek ve elde ettiği verileri iyi değerlendirerek; kortikosteroid, su, sodyum ve glikoz açlığını önceden hissetmek ve hekimle iş birliği halinde çalışarak olası risklerden yola çıkarak olası komplikasyonlardan krizi önlemektir (17) (18).

Sekonder hemşirelik sorumluluğu ise, önleme süreci aş1lmış, tedavi uyumsuzluğu yaşadığı için addison krizi yaşamış ve addison kriziyle acile gelmiş hastayla karşılaştıktan sonra hastayı şok ve koma tablosundan çıkarmak ve yukardaki tedaviye koşullu olarak kriz yönetimi yapmaktır. (17)(19). Hemşire hastada görülebilecek hipotansiyon, hiponatremi, hiperpotasemi, hipoglisemi, ani başlayan sırt, karın ve bacak ağrısı, senkop, şok, şiddetli kusma, diyare ve baş ağrısı gibi adrenal krizin belirti ve bulgularını yakından takip etmelidir. Akut kriz esnasında hastaya sessiz sakin bir çevre sağlanmalı, hastanın en az aktivitede bulunmasına, kriz sonrasında aktivitesini yavaş yavaş arttırmasına dikkat edilmeli, hasta ve ailesine tüm yapılanlar hakkında bilgi verilmeli ve anksiyeteleri azaltılarak stressiz bir yaşam alanı ve yaşam konforu sağlanmalıdır (20). Anormal yaşamsal bulguları olan addison krizli hastalarda hemen siv1 infüzyonu ile intravenöz (IV) Sıvı yüklemesi ihtiyacının sağlanması gerekmektedir. Sıvı hacmini eski haline getirmek için başlangıçta normal salin solüsyonu infüze edilir. Hiperkalemi belirtileri için mümkünse EKG ritmini değerlendirilmelidir. Öğleden sonra veya akşam saatlerinde verilen steroidlerin merkezi sinir sisteminin uyarılmasına ve böylelikle bazı hastalarda uykusuzluğa neden olabileceği için özellikle kortikoterapi ile ilgili tedavi saatleri düzenlenirken dikkate alınmalıdır. Hastanın potasyum seviyesini azaltmak için Kayexalate gibi iyon değişimini sağlayan reçineler, ağızdan veya lavman yoluyla verilebilmektedir. Hasta ve yakınına tedavinin etkisi ve yan etkilerine yönelik bilgi verilmesi gerekmektedir. Günlük kilo izlemi, kortikosteroid uygulama, enfeksiyonlara, travmalara karşı koruma ve hijyeni koruma ve sürdürme önemli hemşirelik girişimleridir. Hastanın cilt rengi ve deri turgoru hipovolemi yönünden düzenli aralıklarla değerlendirilmeli ve günlük kilo takibi yapılmalıdır. Hasta tedavisi sakin bir ortamda sürdürülmeli ve özellikle aşırı gürültü, 1şık ve sıcaklıktan korunmalıdır (15)(9)(10).

Tersiyer hemşirelik sorumluluğunda ise başta hasta olmak üzere, ailesi ve primer bakım vericilerine, evde bakımda dikkat edilmesi gerekenler, yeni bir addison krizini önlemek için uyulması gereken temel ilkeler konusunda bilgi verilmeli, özellikle steroid tedavisinin ömür boyu devam edeceği, tedavinin doktora danışmadan birden kesilmemesi gerektiği, kesildiğinde oluşabilecek komplikasyonlara yönelik konularda eğitim verilmelidir. Bunların yanısıra hasta ve yakınları; hastalık, sıcak hava, enfeksiyon ve operasyon gibi fiziksel ve psikolojik stres durumlarında ilaç dozlarını değiştirmesi için doktoruna hemen haber vermesi gerektiği, , tuz alımını arttırması, aldığı çıkardığı sıvıya dikkat etmesi, hastayı yoracak aşırı aktivitelerden kaçınması, sıcak ve nemli havalarda dışarıda dolaşmaması, yüksek karbonhidratlı ve proteinli gıdalar alması, planlanan izlem randevularını düzenli takip etmesi gerektiği konusunda ayrıntılı olarak bilgilendirilmelidir. Hastaya, yalnızken veya yoldayken olabilecek bir kriz durumunda acil ve doğru müdahale yapılabilmesi için yanında devamlı olarak kimlik kartı, hastalığını ve durumunu belirten tıbbi uyarı bilekliği takması ve yanında acil durumda haber verilmesi gereken tedavisini yürüten doktorunun ve/veya sağlık kuruluşunun iletişim bilgileri yazılı bir kart bulundurması gerektiği konusunda özellikle eğitim verilmelidir (21-23).

\section{Sonuç ve Öneriler}

Sonuç olarak; addison krizi sessiz başlayan, hızlı ve sinsi ilerleyen, birçok organı etkileyen ancak ciddi sonuçlara neden olarak hayatı tehdit eden, ölümle sonuçlanabilen ağır klinik durumdur. $\mathrm{Bu}$ nedenle krizin yönetiminin endokrinolog, yoğun bakım uzmanı, enfeksiyon hastalıkları uzmanı, gastroenterolog, eczacı ve hemşireden oluşan multidisipliner bir ekip tarafından 
yürütülmesi gerekmektedir. Hemşire tedavinin yönetimi, hasta eğitimi, hastanın izlemini ve ekibe hasta il ilgili güncel bilgileri sağlamada önemli bir sorumluluğa role sahiptir. $\mathrm{Bu}$ nedenle öncelikle acil ve endokrin kliniğinde çalışan hemşirelerin başta olmak üzere, özelde dahiliye kliniklerinde görevli genelde ise bütün hemşirelerin; adrenal yetmezlik belirti ve bulgularını bilmeleri, tanımaları ve bakım verdikleri hastaların adrenal bez yetmezlikleri ile ilgili ön belirtilerinin farkında olmaları; primer olarak addison krizini önlemek sekonder olarak krizi yönetmek ve prognozu düzeltmek, tersiyer olarak da addisonlu hastanın kriz sonrası yaşamında yaşam kalitesini yükselten uygulamalar ile yeni krizlerin ortaya çıkmasını önlemek için çok önemli ve gereklidir. $\mathrm{Bu}$ bağlamda addisonlu hastalara her aşamada, addison krizinin belirti ve bulgular konusunda eğitim verilmeli ve hayati bulgularında en ufak bir değişiklik olduğunda, birinci basamak sağlık hizmeti sağlayıcısına başvurmaları konusunda gerekli eğitim planlaması yapılmalıdır. Son olarak, yoğun stresle karşılaştığı zamanlarda, hatta soğuk algınlığında bile; hastaya öncelikle doktoruna danışarak steroid dozunu iki katına çıkarması ve doktoruna ya da birinci basamak sağlık kuruluşuna hemen başvurması gerektiği anlatılmalıdır. Bütün bu hemşirelik bakım ilkelerinin etkin, hızlı ve doğru yapılabilmesi için hemşirenin adrenal yetmezlik ile ilgili kapsamlı bilgi birikiminin ve özellikle de endokrin kliniğinde veya acil serviste görevli ise addison krizi ile ilgili farkındalığının yüksek olması gerekir.

Çıkar Çatışması: Herhangi bir çıkar çatışması yoktur.

Finansal Destek: $\mathrm{Bu}$ makalede herhangi bir finansal yardım alınmamıştır.

Etik Kurul Onayı: Bu makale derleme türünde yazıldığı için etik kurul onayına gerek yoktur.

\section{Yazarlık Katkısı:}

HK: Fikir/Kavram

HK, AT: Tasarım ve Dizayn, Denetleme/Danışmanlık, Kaynak Taraması, Makalenin Yazımı, Eleştirel İnceleme.

\section{Kaynaklar}

1. Hahner S. Acute adrenal crisis and mortality in adrenal insufficiency: Still a concern in 2018! Ann Endocrinol (Paris). 2018;79(3):164-6.

2. Puar THK, Stikkelbroeck NMML, Smans LCCJ, Zelissen PMJ, Hermus ARMM. Adrenal Crisis: Still a Deadly Event in the 21st Century. Am J Med 2016;129(3):339.e1-339.e9.
3. Repping-Wuts HJWJ, Stikkelbroeck NMML, Noordzij A, Kerstens M, Hermus ARMM. A glucocorticoid education group meeting: An effective strategy for improving self-management to prevent adrenal crisis. Eur J Endocrinol. 2013;169(1):17-22.

4. Uçkun S, Kuzucuoğlu T, Temizel F. Ameliyat esnasında gelişen Akut Adrenal Yetmezlik: Olgu Sunumu. Balıkesir Med J. 2019;3(1):5-11.

5. Doğu B, Öksüz H, Şenoğlu N, Yavuz C, Gişi G. Ameliyat sonrası ani hipotansiyonla ortaya çıkan rölatif adrenal yetersizlik. Turk Anesteziyoloji ve Reanimasyon Dern Derg. 2014;42(5):283-7.

6. Türkmen H, Karaca Sivrikaya S. The role of midwife and nurse in pregnancy care with addison's disease. J Educ Res Nurs. 2018;15(3):177-80.

7. Simon DR, Palese MA. Clinical update on the management of adrenal hemorrhage. Curr Urol Rep. 2009;10(1):78-83.

8. Udobi KF, Childs EW. Adrenal crisis after traumatic bilateral adrenal hemorrhage. J Trauma. 2001;51(3):597-600.

9. Dineen R, Thompson CJ, Sherlock M. Adrenal crisis: prevention and management in adult patients. Ther Adv Endocrinol Metab. 2019;10:1-12.

10. Bancos I, Hahner S, Tomlinson J, Arlt W. Diagnosis and management of adrenal insufficiency. Lancet Diabetes Endocrinol. 2015;3(3):216-26.

11. Amrein K, Martucci G, Hahner S. Understanding adrenal crisis. Intensive Care Med. 2018;44(5):652-5.

12. Smans LCCJ, Van Der Valk ES, Hermus ARMM, Zelissen PMJ. Incidence of adrenal crisis in patients with adrenal insufficiency. Clin Endocrinol (Oxf). 2016;84(1):17-22.

13. Miller BS, Spencer SP, Geffner ME, Gourgari E, Lahoti A, Kamboj MK, et al. Emergency management of adrenal insufficiency in children: Advocating for treatment options in outpatient and field settings. J Investig Med. 2020;68(1):16-25. 14. White K, Arlt W. Adrenal crisis in treated Addison's disease: A predictable but under-managed event. Eur J Endocrinol. 2010;162(1):115-20.

15. Hahner S, Allolio B. Management of adrenal insufficiency in different clinical settings. Expert Opin Pharmacother. 2005;6(14):2407-17.

16. Fleming L, Knafl K, Knafl G, Van Riper M. Parental management of adrenal crisis in children with congenital adrenal hyperplasia. J Spec Pediatr Nurs. 2017;22(4):1-10.

17. Shepherd LM, Tahrani AA, Inman C, Arlt W, Carrick-Sen DM. Exploration of knowledge and understanding in patients with primary adrenal insufficiency: A mixed methods study. BMC Endocr Disord. 2017;17(1):1-10.

18. Øksnes M, Björnsdottir S, Isaksson M, Methlie P, Carlsen S, Nilsen RM, et al. Continuous subcutaneous hydrocortisone infusion versus oral hydrocortisone replacement for treatment of addison's disease: A randomized clinical trial. J Clin Endocrinol Metab. 2014;99(5):1665-74

19. Quinkler M, Hahner S. What is the best long-term management strategy for patients with primary adrenal insufficiency? Clin Endocrinol (Oxf). 2012;76(1):21-

20. Todd GRG, Acerini CL, Ross-Russell R, Zahra S, Warner JT, McCance D. Survey of adrenal crisis associated with inhaled corticosteroids in the United Kingdom. Arch Dis Child. 2002;87(6):457-61.

21. Pearce J. Congenital Adrenal Hyperplasia: A Potential Diagnosis for the Neonate in Shock. Aust Crit Care. 1995;8(1):16-9.

22. Moloney S, Murphy N, Collin J. An overview of the nursing issues involved in caring for a child with adrenal insufficiency. Nurs Child Young People. 2015;27(7):28-36.

23. Heart C. Accepted Preprint first posted on 6 October 2014 as Manuscript EJE14-0824 Adrenal Crisis Bruno Allolio. 2014;(October):1-20. 